OPEN ACCESS

Citation: S.J. Kadbhane, V.L. Manekar (2021) Developmentof agro-climatic grape yield model with future prospective. Italian Journal of Agrometeorology (1): 89-103. doi: 10.36253/ijam-406

Received: June 28, 2019

Accepted: June 4, 2021

Published: August 9, 2021

Copyright: @ 2021 S.J. Kadbhane, V.L. Manekar. This is an open access, peer-reviewed article published by Firenze University Press (http://www. fupress.com/ijam) and distributed under the terms of the Creative Commons Attribution License, which permits unrestricted use, distribution, and reproduction in any medium, provided the original author and source are credited.

Data Availability Statement: All relevant data are within the paper and its Supporting Information files.

Competing Interests: The Author(s) declare(s) no conflict of interest.

\section{Development of agro-climatic grape yield model with future prospective}

\author{
S.J. KADBHANE ${ }^{1, \star}$, V.L. MANEKAR ${ }^{2}$ \\ ${ }^{1}$ Civil Engineering MVPS's KBT College of Engineering Nashik, Maharashtra, India. \\ E-mail: sharad_kadbhane@rediffmail.com \\ ${ }^{2}$ Civil Engineering, Sardar Vallabhbhai National Institute of Technology, Surat, Gujarat, \\ India.E-mail:vivek_manekar@yahoo.co.in \\ ${ }^{\star}$ Corresponding author.
}

\begin{abstract}
Agriculture sector is most vulnerable to climate change. To predict the crop yield in accordance with the changing climate is a need of hour than choice. To know the climate in advance is crucial for grape growing farmers and grape export agencies for its better planning and security of grape industries from climate change perspective. In the present study, the Agro-Climatic Grape Yield (ACGY) model is developed on monthly scale climatic parameters using correlation, significance and multi-regression analysis approach. The developed model is statistically tested for its predictive ability. The discrepancy ratio, the standard deviation of discrepancy ratio, mean percentage error and standard deviation of mean percentage error for the developed model is obtained as $1.03,0.19,0.03 \%$ and 0.19 respectively. Sensitivity analysis is carried out for the developed ACGY model using the parametric sensitivity method. In order to know the grape yield for future using developed ACGY model, climate scenarios are generated under Canadian Earth System Model (CanESM2) for three emissions Representative Concentration Pathways (RCP) as RCP2.6, RCP4.5, and RCP8.5. Model response variability is carried out to understand the variation of grape yield. It is observed that grape yield is showing adverse variation with the increase in minimum temperature in January and November months, and precipitation in August and November months. Whereas, minimum temperature in April and sum of monthly mean evapotranspiration showing accordance effect on the grape yield. It is recommended the use of ACGY model for grape yield estimations applicable for the present and future climate of the study area based on the predictive capability of developed model.
\end{abstract}

Keywords: climate change, agro-climatic grape yield models, food security, Grape yield, statistical downscaling.

\section{INTRODUCTION}

The agriculture sector is a backbone of Indian economy. About 58\% of the rural population of India depends on agriculture sector directly or indirectly for the live hood (Srinivastav 2015). As per the Central Intelligence Agency (CIA) fact-book, Indian nation's gross domestic product (GDP) of different sector composed in 2017 is as Services (57.9\%), Industry (24.2\%), and Agriculture 
(17.9\%) (http://statisticstimes.com). Cumulative agriculture production is $\$ 366.92$ billion. India is the second largest producer of the agriculture product in world. India accounts for $7.68 \%$ of total global agricultural output and hence agriculture sector's contribution to the Indian economy is much higher than world's average contribution (6.1\%). According to Agriculture Production Development and Economics Authority, India (APDEA 2016), the agriculture sector has $10 \%$ contribution in the total export of Indian goods. Table Grape (Vitis vinifera cultivars) is one of the important cash crops of the country, which contributes to the socio-economic development particularly of the rural area. In the year 2016, India exported 1.5 Mt of grapes to European and Arabian countries which cost the amount of 15,513 Million Indian Rupees (INR). There is $2 \%$ export contribution of grape among all fruits cultivated in India; out of that $90 \%$ grapes are exported only from the Nashik district (Saxena, 2014).

The productivity of grape is highest in India among grape growing countries in the world (FAO 2016). In the country, Maharashtra is a highest grape producing state. Specifically, within Maharashtra state, Nashik district is a highest grape producing. Grape has potential to generate a large amount of employment. On an average, in India, one hectare grape orchard is offering employment to five people throughout the year. Among all districts of India, Nashik is the largest grape producer (APDEA, 2016). The socio-economic growth of the rural area of the Nashik district is mostly due to grape crop and its export potential.

It is well known and accepted fact that agriculture sector is highly impacted by climate change than any other sector. Globally, the effect of climate change is indicating the increase in temperature and decrease in precipitation (IPCC 2013). In Indian subcontinent, large variations are noticed in the occurrences of precipitation. There are chances of meteorological, agricultural, and hydrological drought due to such kind of variations and larger gap in the precipitation occurrences (Bowden and Bormann 1986).

Under such circumstances, it becomes difficult to predict the crop yield. Weather effects and adaptation approaches are increasingly becoming major zones of research on crop production worldwide (Hoogenboom, 2000; Yinhong et al., 2009). A condition where there is an effect of climate can have the theatrical situation and affect the food security of billions of people (Abbaspour, 1994; Droogers, 2004). An understanding of climate impact over the crop quality and quantity is essential in predicting the yield (Adams et al., 2003). The variations in crop yield associated with climatic parameters will probably have key influences on local and universal food production (Abraha and Savage, 2006).
Prediction of climate in advance is crucial to grape growing farmers and grape export agencies for its better planning and security of grape industries from climate change perspective. The estimation of yield is another important issue related to the grape industry. It is revealed from the literature survey that there are many yield estimating models available for crops like wheat, rice, maize, sorghum, sugarcane, etc., but for the estimation of grape yield need to develop new models (Zhang and Shen, 2008). Moreover, models are observed as location specific with limited variables involved in the model. There is no evidence of any model reported in the literature so far for the estimation of grape yield of Indian terrain. Therefore, it is felt that there is an urgent need for such agro-climatic grape yield (ACGY) model which can estimate the yield considering significant parameters together and which can represent the grape yield process in accordance with the climate. It is also revealed from the literature survey that crop yield models are performing better on the local scale than global scale. Hence, the present study is undertaken to develop Agro-Climatic Grape Yield (ACGY) model for the study area as Nashik district with reference to the current and future climate.

\section{MATERIALS AND METHODS}

In the present study, it is tried to developed ACGY model using parameters mainly from the domain of climate. In the development of ACGY model, the parameters from the climate domain are considered as temperature, precipitation, relative humidity, sunshine hour, and evapotranspiration. Climate data is collected from India Meteorological Department (IMD) India. Soil domain data is collected by field survey, and laboratory testing at National Horticultural Research and Development Foundation (NHRDF) Niphad. All grape plants are of common variety cultivated in the study area, namely Thompson seedless. The planted spacing between rows is $2.4 \mathrm{~m}$ and spacing between plants is $1.2 \mathrm{~m}$. A drip irrigation system is used. The training system mostly used is $\mathrm{T}$ and $\mathrm{Y}$ shape trellis structure, for high yields of grape plant. In the study area from March to May temperature is high, there is no precipitation and low humidity. Whereas from June to October temperature is low, precipitation and humidity are high. From November to February, there is low temperature, rare rainfall and low humidity. Based on the recommended ranges of the various properties of the soil, it is found that the soil of the study area is of good quality for yielding grape. Study area has good characteristics and climatic conditions for production of grape. 


\subsection{Location details of study area}

The location of the Nashik district is $18^{0} 19^{\prime} 48^{\prime \prime}$ to $20^{\circ} 31^{\prime} 48^{\prime \prime} \mathrm{N}$ latitude and $73^{\circ} 09^{\prime} 36^{\prime \prime}$ to $75^{\circ} 09^{\prime} 17^{\prime \prime}$ E longitude at the North-West part of Maharashtra state, at 565-meter altitude. Nashik district is having total fifteen talukas, namely Nashik, Surgana, Trimbak, Peint, Igatpuri, Niphad, Sinnar, Dindori, Kalwan, Yeola, Nandgaon, Chandwad, Satana, Deola, and Malegaon. According to the census report 2011, the district includes 1931 villages (https://nashik.nic.in).

\subsection{Phenological stages and climatic associations of grape plant}

The phenological cycle of the grape plant in the tropical and subtropical region includes phases of dormancy, active vegetation, reproductive development, and growth. The grape plant has mainly six phenological stages i.e. bud breaking, flowering, berry set, berry growth, veraison and harvest. In the study area grape plant is broadly having two pruning cycles such as foundation pruning (April to September) and fruit pruning (October to March). Near about $90 \%$ of grape orchards are following this schedule except color varieties and vineyards located in the Northern region of Nashik district. The evolution of the phenological phases or the particular monthly variation in the climate plays a vital role in the grape production (Adsule, 2013). Fruit pruning takes place in the first week of October. In this particular stage, due to decrease in temperature or increase in humidity or decrease in evapotranspiration or occurrence of rainfall, either all or any one of these parameters affecting the bud break and lead to induce fungal disease. If rainfall occurs in the month of October, then there are major chances of having the fungal disease which also disturb the vegetative growth. In the month of November, most of the grape orchards are under the phenological stage of flowering. The flowering stage is found to be very sensitive towers humidity and rainfall. If rainfall occurs during the flowering stage, grape clusters get heavily damage and flowers are not able to convert into the berry. The berry growth phenological stage is observed in the month of December and January andthe temperature affects the growth of the berry.

\subsection{Pearson correlation and regression coefficient}

Correlations and regressions aim at defining the relationship among parameters. The aim of this method is to investigate the significant correlation between one or more dependent and independent variables (Gupta, 1981). A sample correlation coefficient between the $X$ and $Y$ variables can be found using Pearson correlation coefficient ( $r$ ) and defined as given in Eq.(1).

$$
r=\frac{\operatorname{cov}(X, Y)}{S_{X}-S D_{Y}}=\frac{\frac{1}{n} \sum_{i=1}^{n}\left(x_{i}-M_{X}\right)\left(y_{i}-M_{Y}\right)}{\sqrt{\frac{1}{n} \sum_{i=1}^{n}\left(x_{i}-M_{X}\right)^{2}} \sqrt{\frac{1}{n} \sum_{i=1}^{n}\left(y_{i}-M_{Y}\right)^{2}}}
$$

Where, $\operatorname{cov}(\mathrm{X}, \mathrm{Y})$ is the covariance among $\mathrm{X}$ and $\mathrm{Y}$, $\mathrm{SD}_{\mathrm{X}}$ and $\mathrm{SD}_{\mathrm{Y}}$ are the standard deviations of the series of variables, $X$ and $Y$ are the series of variables, $M_{X}$ and $M_{Y}$ are mean of the series of variables, and $\mathrm{X}_{\mathrm{i}}$ is independent variable and $y_{i}$ dependent variable. Pearson correlation coefficient $(r)$ can be calculated using the original values of $\mathrm{X}$ and $\mathrm{Y}$. Essentially, $r$ is $-1 \leq r \leq 1$ showing negative and positive values of $r$ indicating linear correlation between $\mathrm{X}$ and $\mathrm{Y}$, both associates with large values. If $\mathrm{r}$ is zero, then there is no linear correlation.

\subsection{Multi-regression analysis}

The prediction capability of any model is dependent on the model parameters representing that model. Selection of model parameters, if selected, based on their level of significance improves the model performance. It also depends upon the total number of model parameters involved in the model. Therefore, the selection of model parameters is a crucial stage in the model development. It is revealed from the literature survey that climatic conditions during the phenological stages of grape plant plays an important role in deciding the yield. Hence, to develop ACGY model, the most significant climatic parameters at the phenological stages should be selected after carrying out the separate regression analysis for each of the selected parameters. The climatic parameter such as temperature and precipitation always shows the non-monotonic effect on the crop yield. Model variables from the domain of climate, soil, and irrigation practices are seem to be most significant for the grape yield. In the development of such models, which need the involvement of multi-parameters, it is found that multi-regression analysis technique is the most appropriate technique due to the advantage of getting freedom in selecting multi parameters (Gupta, 1981). Hence, in the development of ACGY model, selection of variable based on statistical relationship and grape phenology is used in its development. The parameters from the domain of climate, soil, and irrigation practices are considered in the development of the agro-climatic grape yield (ACGY) model using the multi-regression analysis. The basic form of the multi-regression model is indicated below in Eq. (2). 
$\mathrm{Y}=\mathrm{C}+\alpha_{1} \mathrm{X}_{1}+\alpha_{2} \mathrm{X}_{2}+\alpha_{2} \mathrm{X}_{3}+\alpha_{\mathrm{n}} \mathrm{X}_{\mathrm{n}}$

Where $\mathrm{Y}$ is a dependent parameter, $\mathrm{C}$ is the value of $y$ when all the independent variables are zero, $\alpha_{1}, \alpha_{2 \ldots . . .}$ $\alpha_{n}$ are regression coefficients and $X_{1}, X_{2}, X_{3}, \ldots X_{n}$ are independent parameters. The regression coefficients are estimated using. Eq.(3).

$\alpha=\left(\frac{r_{y x j}-r_{y x i} r_{x i, x j}}{1-\left(r_{x i, x j}\right)^{2}}\right)\left(\frac{S D_{y}}{S D_{x j}}\right)$

Where $\alpha$ is the regression coefficients, $r$ is the correlation coefficient, $S D$ is the standard deviation, $i$ and $j$ are the sample parameters from the series $\mathrm{x}$ and $\mathrm{y}$.

\subsection{Comparison of data samples using t-test}

The objective of t-test is to equate two unpaired sets of data and apply to non-continuous or continuous data (Gupta, 1981). The t-statistics can be calculated by estimating the pooled variance. Initially, the estimation of unbiased pooled variance is carried out using Eq. (4).

$V=\frac{V_{A}\left(N_{A}-1\right)+V_{B}\left(N_{B}-1\right)}{V_{A}+V_{B}-2}$

Where, $\mathrm{V}$ is unbiased pooled variance, $\mathrm{N}_{\mathrm{A}}$ and $\mathrm{N}_{\mathrm{B}}$ are the number of data point in group $\mathrm{A}$ and $\mathrm{B}$ and $\mathrm{V}_{\mathrm{A}}$ and $V_{B}$ are variances of groups $A$ and $B$.

The standard error using unbiased pool variance is calculated using Eq. (5).

$S E=\sqrt{V\left(\frac{1}{N_{A}}+\frac{1}{N_{B}}\right)}$

The $\mathrm{t}$-statistics are calculated as the ratio of using difference of the means and the standard error as shown below in Eq. (6).

$t=\frac{M_{A}-M_{B}}{S E}$

Where $M_{A}$ and $M_{B}$ are mean of group $A$ and $B$ respectively.

\section{$2.6 p$-values}

Once the t-statistics value and degree of freedom are determined then $\mathrm{p}$-value is determined by using t-statistics table. Once hypotheses, $\mathrm{H}_{0}$ (data samples created from the similar parameter data set), and $\mathrm{H}_{1}$ (most data sample created from different parameter data set) is true then p-value $(<0.05)$ is an approximate value adapted as significant value (Gupta, 1981). It is indicated that there should be $5 \%$ possibility of incorrectly identifying the significant change ( $\mathrm{p}$-value $<0.05$ ) i.e. $5 \%$ significance level, it means $95 \%$ confidence interval.

\subsection{Parametric and component sensitivity method}

Any system is cover under three functions such as the output functions, transfer function, and input functions. The transfer function converts the input function into the output function. Hence, this function could be the probability distribution function which depends on one or more variables.

The sensitivity analysis of the mathematical model is to find out the parametric variation on the output. The parametric sensitivity is algebraically expressed as given in Eq. (7).

$S_{p i}=\frac{\partial O}{\partial P_{i}}=\frac{f\left(P_{i}+\Delta P_{j} ; P_{j l j \neq i}\right)-f\left(P_{1}, P_{2} \ldots \ldots, P_{n}\right)}{\Delta P_{i}}$

Here, $\mathrm{O}$ is output functions and $\mathrm{Pi}$ represent response function parameter. In general, crop yield models are more complex, so it is difficult to compute the parametric sensitivity. Hence, by considering the input and output function, sensitivity can be defined. Therefore, component sensitivity is found using input function on the output function $\mathrm{O}$ as shown in the Eq. (8).

$\frac{\partial O}{\partial I}$

The relative sensitivity value (RSV) of the input can be computed. Here, the mean values, the relative sensitivity of output parameters $\mathrm{O}_{i}$ and $\mathrm{O}_{j}$ to the input $\mathrm{Pi}$ and $\mathrm{Pj}$ would be estimated using Eq. (9 and 10)

$R_{s i}=\frac{\partial O i}{\partial P_{i}}\left(\frac{\bar{P}_{l}}{\bar{o}_{i}}\right)$

$$
R_{s j}=\frac{\partial o_{j}}{\partial P_{j}}\left(\frac{\overline{P_{j}}}{\bar{o}_{j}}\right)
$$


Where, $\mathrm{R}_{\mathrm{si}}$ and $\mathrm{R}_{\mathrm{sj}}$ are the relative sensitivity values, $\left(\partial \mathrm{O}_{\mathrm{i}} / \partial \mathrm{P}_{\mathrm{i}}\right)$ and $\left(\partial \mathrm{O}_{\mathrm{j}} / \partial \mathrm{P}_{\mathrm{j}}\right)$ are the coefficient of input parameters $\bar{P}_{2}$ and $\bar{P}_{J}$ (the mean of input parameters) and $\bar{O}_{i}$ and $\bar{O}_{j}$ the mean of the output parameter. The higher value of relative sensitivity $R_{s i}$ and $R_{s j}$ indicates greater the impact of the input parameter on output parameters.

\subsection{Forecasting of climate}

Several climate predicting models are reported in the literature. General circulation models (GCMs) are reported to acquire climate data on the global scale or large scale. Due to coarser resolution, it becomes essential to downscale this data to regional or local scale. Large numbers of such models are available, which explore the relationship between large scales to local scale data. In this study statistical downscaling model (SDSM) is used for predicting future climate. Using SDSM, different climate scenarios under different climatic conditions are possible to generate (Wilby et al., 2002). Ocean element has 40 vertical layers, 10 $\mathrm{m}$ approximately resolution and $1.410^{\circ} \mathrm{N} \times 0.940^{\circ} \mathrm{E}$ horizontal resolution (Hoskin, 1980). The CanESM2 is organized for Coupled Model Inter-comparison Project Phase 5 (CMIP5), (Taylor et al., 2012) and this is mainly the involvement for IPCC Fifth Assessment Report (AR5) (Arora and Boer, 2014). Different scenarios are used at various stages of time in climate research according to IPCC's first SRES (Special Report on Emissions and Scenarios) used in the third and fourth report of assessment. During 2013-14, IPCC $5^{\text {th }}$ Assessment Report (AR5) was published. The results are the basis of new scenarios set that replaced the SRES. The Representative Concentration Pathways (RCPs) are new scenarios and it is the latest iteration of the scenario process. These are four pathways such as RCP 2.6. 4.5, 6, and 8.5. The RCPs are developed using the combined efforts of the researchers from different disciplines involved in climate research (Van Vuuren et al., 2011). They are named at the end of the $21^{\text {st }}$ century based on the radiative forcing target 2.6. 4.5, 6 , and $8.5 \mathrm{~W} / \mathrm{m}^{2}$. In this study mainly RCP $2.6,4.5$, and 8.5 are considered for forecasting the future climate.

\section{RESULTS AND DISCUSSIONS}

\subsection{Selection of model parameters}

It is tried to cover up the maximum and significant parameters in the model development which represents the entire phenomenon of the grape yield significantly.
In order to develop a meaningful relationship between the dependent and independent variables of the yield process, functionally grape yield can be written as shown below in Eq. (11);

$\mathrm{Y}=\mathrm{f}\left(\mathrm{T}, \mathrm{P}, \mathrm{S}_{\mathrm{h}}, \mathrm{R}_{\mathrm{h}}, \mathrm{ETo}\right)$

Where, $\mathrm{Y}$ is a Grape yield (ton/ ha); T is Temperature (the monthly minimum, maximum, average in ${ }^{\circ} \mathrm{C}$ ); $\mathrm{P}$ is Precipitation (monthly total $\mathrm{mm}$ ); $\mathrm{S}_{\mathrm{h}}$ is Sunshine hours (hr); $\mathrm{R}_{\mathrm{h}}$ is Relative humidity (\%), and $\mathrm{ET}_{\mathrm{o}}$ is reference evapotranspiration $\left(\mathrm{mm} \mathrm{day}^{-1}\right)$.

\subsection{Correlation analysis for yield with climatic parameters}

Climatic parameters are shown the effect on crop yield throughout the phenological stages of the grape crop. It is difficult to find out the relationship between yield and climatic parameters due to its scale of variability from day to day and month to month. To check the correlation of these climatic parameters, correlation analysis is carried out for the dependent parameter and independent parameter using $70 \%$ data i.e. during the period 1991-2008. Temperatures are observed on daily scale as minimum, maximum, and average. Correlation analysis is carried out for monthly mean minimum temperature, monthly mean maximum temperature, and monthly mean average temperature with the grape yield. Whereas, precipitation considered as monthly total precipitation. Relative humidity (\%) and Sunshine hours (hr) are considered as monthly mean values. Evapotranspiration $\mathrm{ET}_{\mathrm{o}}(\mathrm{mm} /$ day $)$ is the important parameter of the crop yield model which essentially exists throughout the year. Therefore $\mathrm{ET}_{\mathrm{o}}$ is considered on the annual scale. Correlation coefficient value ranges between +1 to -1 . The results of correlation analysis are shown below in Table 1.

Based on the obtained results, as shown in Table 1 , the value of correlation coefficient equal to or greater than \pm 0.3 is considered as a correlated variable, and there is exists a correlation between independent variables and dependent variables (Nikolić et al., 2012). Accordingly, there exists a correlation between yield and i) monthly mean average temperature in the month of June and September, ii) monthly mean maximum temperature in the month of May, July, and February, iii) monthly mean minimum temperature in the month of April, November, and January, iv) monthly precipitation in the month of August, September and November, v) relative humidity in the month of August, September, and November and vi) sunshine hours in the month of April, October, November, and January; vii) 
Table 1. Results of correlation analysis between monthly climatic parameters and grape yield.

\begin{tabular}{|c|c|c|c|c|c|c|c|c|c|c|c|c|}
\hline $\begin{array}{l}\text { Months } \rightarrow \\
\text { Monthly } \downarrow\end{array}$ & Apr & May & Jun & Jul & Aug & Sep & Oct & Nov & Dec & Jan & Feb & Mar \\
\hline $\begin{array}{l}\text { Mean Avr. Temperature } \\
\left(\operatorname{Tav}^{\circ} \mathrm{C}\right)\end{array}$ & 0.12 & -0.07 & 0.30 & 0.18 & 0.20 & 0.30 & 0.12 & -0.13 & 0.13 & -0.01 & -0.05 & 0.09 \\
\hline $\begin{array}{l}\text { Mean Max. Temperature } \\
\left(\operatorname{Tmax}^{\circ} \mathrm{C}\right)\end{array}$ & -0.01 & 0.40 & -0.07 & 0.54 & -0.21 & 0.24 & 0.17 & 0.19 & 0.08 & -0.13 & -0.67 & -0.10 \\
\hline $\begin{array}{l}\text { Mean Min. Temperature } \\
\left(\operatorname{Tmin}{ }^{\circ} \mathrm{C}\right)\end{array}$ & 0.35 & -0.24 & 0.00 & 0.09 & -0.02 & 0.09 & -0.28 & -0.55 & 0.02 & -0.54 & -0.28 & -0.13 \\
\hline Precipitation (P mm) & -0.09 & 0.04 & -0.20 & -0.11 & -0.30 & 0.32 & 0.12 & -0.79 & -0.22 & 0.14 & -0.05 & 0.15 \\
\hline R. Humidity (Rh \%) & -0.18 & -0.14 & 0.09 & -0.06 & -0.40 & -0.34 & 0.05 & -0.35 & -0.22 & 0.01 & 0.06 & -0.10 \\
\hline Sunshine hours (Sh hr) & 0.53 & -0.29 & 0.24 & 0.23 & 0.11 & -0.07 & 0.45 & -0.54 & 0.09 & 0.39 & -0.02 & 0.09 \\
\hline ETo (mm/day) & 0.53 & -0.67 & -0.23 & 0.11 & -0.21 & -0.11 & -0.07 & 0.73 & 0.49 & 0.24 & 0.21 & -0.33 \\
\hline
\end{tabular}

ETo in the month of April, May, November, December and March. Evapotranspiration is observed to be significant in the phenological cycle of the grape plant. The evapotranspiration of plants significantly influences the yield of grapes in all phenological phases (Netzer et al., 2009) and consequently in the further analysis the unit for evapotranspiration is considered as monthly average $\mathrm{mm}$. Thereafter, all these independent variables which are highly correlated with the grape yield are considered in the further analysis.

\subsection{Significance analysis using t-stat and p-test}

The above mentioned variables which are showing correlation are considered for their significance testing. The t-stat and p-test are carried out using MicrosoftExcel 2010 data analysis tool to check the significance of the variables. If the $\mathrm{p}$-value of the variable is found to be less than 0.05 , then it is considered as significant and considered further in the construction of the model. The $\mathrm{t}$-stat and p-value results are shown below in Table 2 .

It is observed from the obtained results of $t$-stat and $\mathrm{p}$-value that results, there is no significant relationship among yield and the climatic parameters such as monthly mean average, monthly mean maximum temperature, relative humidity and sunshine hours as p-value are observed to be greater than 0.05 and hence the monthly mean average, monthly mean maximum temperature, relative humidity and sunshine hours are discarded from the consideration of parameters in the model development. It is observed that P-value showing less than 0.05 for the monthly mean minimum temperature in the month of January, April and November, precipitation in the month of August and the November and sum of monthly mean evapotranspiration as shown in Table 2. Hence, these parameters are considered to be statistically significant and are considered as the model parameters in the development of ACGY model.

Table 2. Results of $\mathrm{t}$-stat and p-value of model parameters.

\begin{tabular}{|c|c|c|c|c|c|c|c|}
\hline Parameters & Month & t-stat & p-value & Parameters & Month & t-stat & $\mathrm{p}$-value \\
\hline \multirow{2}{*}{$\begin{array}{l}\text { Monthly Mean Avr. } \\
\text { Temp }\left({ }^{\circ} \mathrm{C}\right)\end{array}$} & Jun & -0.03 & 0.976 & \multirow{3}{*}{$\begin{array}{l}\text { Relative Humidity } \\
(\%)\end{array}$} & May & -0.608 & 0.586 \\
\hline & Sep & 0.96 & 0.349 & & Jun & -0.468 & 0.672 \\
\hline \multirow{3}{*}{$\begin{array}{l}\text { Monthly Mean Max. } \\
\text { Temperature } \\
\left({ }^{\circ} \mathrm{C}\right)\end{array}$} & Feb & -0.44 & 0.670 & & Aug & 0.468 & 0.672 \\
\hline & Apr & 0.95 & 0.380 & \multirow[t]{6}{*}{ Sunshine hour (hr) } & Apr & -0.511 & 0.631 \\
\hline & Nov & -1.56 & 0.170 & & May & -0.036 & 0.973 \\
\hline \multirow{3}{*}{$\begin{array}{l}\text { Monthly Mean Min. } \\
\text { Temperature } \\
\left({ }^{\circ} \mathrm{C}\right)\end{array}$} & Jan & -3.35 & 0.000 & & Jun & 0.573 & 0.591 \\
\hline & Apr & 2.35 & 0.030 & & Aug & -0.252 & 0.811 \\
\hline & Nov & -2.17 & 0.040 & & Nov & -1.730 & 0.144 \\
\hline \multirow{3}{*}{$\begin{array}{l}\text { Monthly } \\
\text { Precipitation (mm) }\end{array}$} & Aug & -2.48 & 0.023 & & Dec & -0.095 & 0.928 \\
\hline & Sep & 0.79 & 0.438 & \multirow[t]{2}{*}{ ETo (mm) } & \multirow[t]{2}{*}{ Annual } & \multirow[t]{2}{*}{2.02} & \multirow[t]{2}{*}{0.040} \\
\hline & Nov & -5.48 & 0.000 & & & & \\
\hline
\end{tabular}


As per the phenological study of grape plant, August and November month precipitation is highly sensitive towards grape yield. Physically, during the month of August if heavy rainfall occurs, the roots of the vine go into asphyxiation and significantly affect growth. Also, during the month of November, $80 \%$ of vineyards are in the phenological stage known as flowering in the study area. On receiving precipitation during this stage, the berry setting cycle get disturbed and it shows the adverse effect on the grape production. It is also noticed from the literature that crop production is most delicate to precipitation than temperature (Popova et al. 2005; Akpalu et al.2008). Hence, the relationship between grape yield and minimum temperature in the month of January, April, and November, precipitation in the month of August and November and sum of monthly mean evapotranspiration is obtain using multi-regression approach. Selection of parameters is the crucial stage in model development. Based on the grape yield phenological stages and weather effects model parameters are selected.

\subsection{Agro-climatic grape yield model}

Correlation analysis is carried out for screening the most correlated climatic parameters with yield. The ACGY model is developed by using the approach of multi-regression analysis. In the process of model development, grape yield is considered as dependent parameter and climatic parameters as independent parameters. Accordingly, coefficients for the model parameters are obtained from the multi-regression analysis and estimated model coefficients are summarized as shown below in Table 3.

It is observed from Table 3, that the model intercept is -44.67 , the coefficient for the monthly mean minimum temperature for January month $\left(\mathrm{T}_{\mathrm{ja}}\right)$ is -1.60 , the coefficient for the monthly mean minimum temperature for April month $\left(\mathrm{T}_{\mathrm{ap}}\right)$ is 1.33 , the coefficient for monthly mean minimum temperature for November month $\left(\mathrm{T}_{\mathrm{n}}\right)$ is -0.49 , the coefficient of total monthly precipitation for August month $\left(\mathrm{P}_{\mathrm{au}}\right)$ is -0.01 , the coefficient of total monthly precipitation for November $\left(\mathrm{P}_{\mathrm{n}}\right)$ month is -0.15 , and the coefficient for the sum of monthly mean evapotranspiration (ETo) is 0.94. Hence using intercept and coefficient value of parameters as shown in Table 3 the model is formed as shown below Eq. (13).

$\mathrm{Y}=\left(-44.67-1.60 \mathrm{~T}_{\mathrm{ja}}+1.33 \mathrm{~T}_{\mathrm{ap}}-0.49 \mathrm{~T}_{\mathrm{n}}-0.01 \mathrm{P}_{\mathrm{au}}\right.$
$\left.-0.15 \mathrm{P}_{\mathrm{n}}+0.94 \mathrm{ETo}\right)$

Where, $\mathrm{Y}=$ Grape yield $\left(\right.$ ton ha $\left.{ }^{-1}\right) ; \mathrm{T}_{\mathrm{ja}}=$ Monthly mean minimum temperature in the month of January $\left({ }^{\circ} \mathrm{C}\right) ; \mathrm{T}_{\text {ap }}=$ Monthly mean minimum temperature in the month of April $\left({ }^{\circ} \mathrm{C}\right) ; \mathrm{T}_{\mathrm{n}}=$ Monthly mean minimum temperature in month of November $\left({ }^{\circ} \mathrm{C}\right) ; \mathrm{P}_{\mathrm{au}}=$ total monthly precipitation in the month of August $(\mathrm{mm}) ; \mathrm{P}_{\mathrm{n}}=$ Total monthly precipitation in the month of November $(\mathrm{mm})$; $\mathrm{ET}_{\mathrm{o}}=$ Sum of monthly mean evapotranspiration $(\mathrm{mm})$.

\subsection{The validation of developed ACGY model (Eq. 13)}

Recommendation for applicability of the developed ACGY model (Eq.13) is based on its validation performance. The independent datasets are used for the purpose of validation (2009-2016) which is other than the data used in the development of the model (Eq.13). For validation of the above ACGY model, 30\% independent data set of climatic parameter and yield during the years 2009 to 2016 is used. Using independent data set and the developed ACGY model (Eq.13), the grape yield is estimated and compared with the observed grape yield. A plot between the observed and predicted grape yield is shown below in Figure 1.

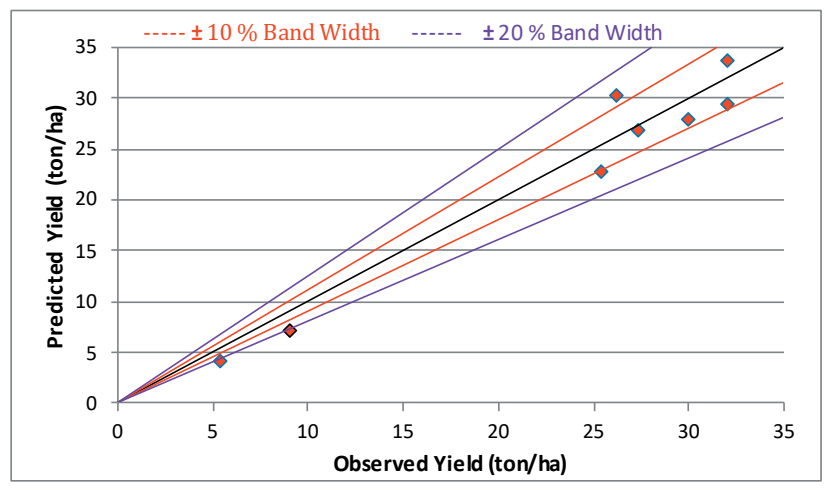

Fig. 1. Validation plot of the developed ACGY model Eq. 13 (20092016).

Table 3. Coefficient for model parameters.

\begin{tabular}{lccccccc}
\hline & Intercept & Tmin. Jan. $\left(\mathrm{T}_{\mathrm{ja}}\right)$ & Tmin. Apr. $\left(\left(\mathrm{T}_{\mathrm{ap}}\right)\right.$ & Tmin. Nov. $\left(\mathrm{T}_{\mathrm{n}}\right)$ & Pre. Aug. $\left(\mathrm{P}_{\mathrm{au}}\right)$ & Pre. Nov. $_{\left(\mathrm{P}_{\mathrm{n}}\right)}$ & ET $_{\mathrm{o}}$ \\
\hline Coefficients & -44.67 & -1.60 & 1.33 & -0.49 & -0.01 & -0.15 & 0.94 \\
\hline
\end{tabular}


From the validation plot, as shown in Figure 1, it is observed that $62.5 \%$ of data points fall within $\pm 10 \%$ bandwidth and remaining $37.5 \%$ data point fall within $20 \%$ bandwidth. This confirms the predictive capability of the developed model (Eq. 13).

Further, the sensitivity analysis is carried out to understand the most sensitive agro-climatic parameters of the developed ACGY model (Eq.13) which affect the model output more with small variation within them. Sensitivity analysis is carried out as described below.

\subsection{Sensitivity Analysis}

It is revealed from the literature survey that parametric and component sensitivity analysis method is found more appropriate to carry out the sensitivity analysis of grape yield model (Hamby 1994). Using parametric and component sensitivity method Eq. (10) the relative sensitivity values are obtained for each parameter of the developed model. Eq. (10) is use to calculate the relative sensitivity value (RSV) which require the component like $\bar{O}_{i}, \bar{P}_{\imath}$ and $\left(\partial \mathrm{P}_{\mathrm{i}} / \partial \mathrm{O}_{\mathrm{i}}\right)$. The value of mean output parameter $\left(\bar{O}_{i}\right)$ (mean of grape yield 1991 to 2016 ) is $22.49 \mathrm{t} / \mathrm{ha}$ and the values of mean of input (independent) parameters $\bar{P}_{v}$, coefficient estimated using multi-regression analysis $\left(\partial \mathrm{P}_{\mathrm{i}} / \partial \mathrm{O}_{\mathrm{i}}\right)$, as shown in Table 3 and RSV are summaries in Table 4.

The parameters obtain the higher value of relative sensitivity (RSV) indicating a higher sensitivity of that parameter. From the obtained results, sum mean monthly evapotranspiration (ETo) is found to be most sensitive as it has highest relative sensitivity value (RSV) as 3.24. Whereas, monthly total precipitation in August $\left(\mathrm{P}_{\mathrm{au}}\right)$ is having lowest value of relative RSV as -0.08 , indicates less sensitivity of the parameter. This helps in understanding the parametric variations on the model output. Now the developed agro-climatic grape yield (ACGY) model is tested for its statistical performance as described below.
Table 5. Statistical performance of the developed ACGY model (Eq.13).

\begin{tabular}{lc}
\hline Statistical tests & $\begin{array}{c}\text { Developed ACGY model (Eq.13) } \\
\text { (ton/ ha) }\end{array}$ \\
\hline Discrepancy ratio ( $\mathrm{r}$ ) & 1.03 \\
Standard Deviation of $\mathrm{r}$ & 0.19 \\
Mean Percentage Error (MPE) & 0.03 \\
Standard Deviation of MPE & 0.19 \\
\hline
\end{tabular}

3.7 The statistical performance of developed agro-climatic grape yield (ACGY) model

It is revealed from the literature review that there is no evidence of having any agro-climatic grape yield model for Indian Terrain. The statistical fitness of the developed ACGY model (Eq.13) is tested using statistical tests such as discrepancy ratio (r), the standard deviation of $\mathrm{r}$, mean percentage error (MPE) and standard deviation of MPE. The discrepancy ratio $(r)$ is the ratio of simulated grape yield and observed grape yield. The ideal value of the discrepancy ratio should be one. The mean percentage error (MPE) is calculated as the difference of simulated grape yield and observed grape yield divided by observed crop yield in percentage. The obtained results of the statistical performance carried out for developed ACGY model Eq. (13) is shown below in Table 5.

It is observed from the Table 5 that the discrepancy ratio for developed model (Eq.13) is 1.03 which is very close to its ideal value of one. Mean percentage error of developed model is $0.03 \%$. The standard deviation of discrepancy ratio and mean percentage error is observed as 0.19 . From the obtained results of the statistical performance, it is observed that the developed model (Eq.13) is performing satisfactory. Besides this, results of model yield and actual yield are compared by considering the data during 1992 to 2016 which shown in Figure 2.

Table 4. Results of sensitivity analysis.

\begin{tabular}{|c|c|c|c|}
\hline Climatic parameters & $\begin{array}{c}\text { Mean } \\
\left(\overline{P_{2}}\right)\end{array}$ & $\begin{array}{l}\text { Coefficient } \\
\left(\partial \mathrm{P}_{\mathrm{i}} / \partial \mathrm{O}_{\mathrm{i}}\right)\end{array}$ & RSV \\
\hline Monthly mean min. temperature in January $\left(\mathrm{T}_{\mathrm{ja}}\right)$ & $14 . \overline{36}$ & -1.60 & -1.02 \\
\hline Monthly mean min. temperature in April $\left(\mathrm{T}_{\mathrm{ap}}\right)$ & 23.19 & 1.33 & 1.37 \\
\hline Monthly mean min. temperature in November $\left(T_{n}\right)$ & 17.83 & -0.49 & -0.39 \\
\hline Monthly total precipitation in August $\left(\mathrm{P}_{\mathrm{au}}\right)$ & 181.28 & -0.01 & -0.08 \\
\hline Monthly total precipitation in November $\left(\mathrm{P}_{\mathrm{n}}\right)$ & 18.07 & -0.15 & -0.12 \\
\hline Sum of monthly mean Evapotranspiration $\left(\mathrm{ET}_{\mathrm{o}}\right)$ & 77.63 & 0.94 & 3.24 \\
\hline
\end{tabular}




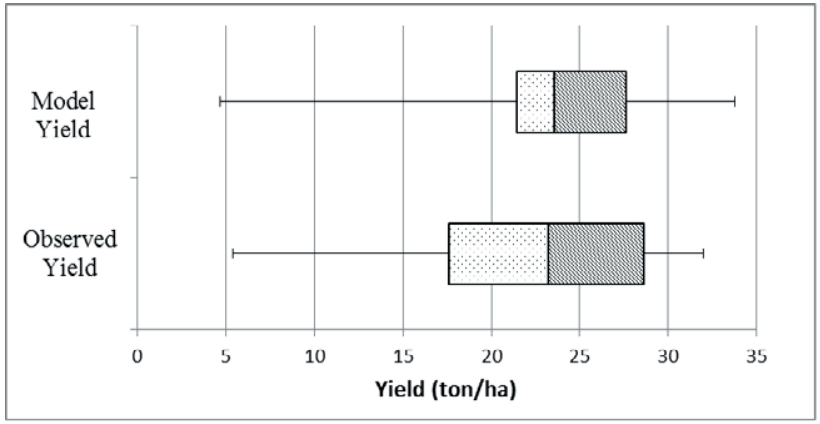

Figure 2. Comparison between observed yield and model yield (Eq. 13) (1992-2016).

Figure 2 shows the box plot of observed yield and model yield (Eq. 13). Accordingly, it is observed that median of developed ACGY model is 23.5 (ton/ha) and that observed data is 23.2 (ton/ha). The upper quartile and lower quartile values are close to the median value of model yield as compared to observed yield. Hence, it is recommended that the developed ACGY model is found suitable to predict the grape yield for the study area.

3.8 Climate plot between ACGY model estimated grape yield and climate variables under three RCPs during 20212050

It is more interesting to see the variations of the model yield with climate variables for all the 30 years (2021-2050). Hence, the climate plot between ACGY model estimated grape yield and climate variables under RCP 2.6, 4.5 and 8.5 during 2021-2050 is plotted and shown below in Figures 3, 4, 5, 6, 7 and 8 .

It has been noticed from the plot shown in Figures 3 and 4 that the lowest crop yield is observed as 18.63 ton/ ha in the year 2049 wherein November precipitation is predicted as $72.36 \mathrm{~mm}$ which is the highest precipitation during the years 2021-2050. The maximum crop yield is observed in the year 2047 as 28.64 ton/ha for which the sum of monthly average evapotranspiration in this year is observed highest as $77.55 \mathrm{~mm}$ among all years under RCP2.6. Hence from the Figures 3 and 4 it is observed that evapotranspiration and temperature in April show a positive impact on yield, whereas, the temperature in January, November, precipitation in August and November shows a negative impact on yield Similarly, the climate variables generated under RCP4.5 are comparing with the predicted grape yield during 2021-2050. Climate plot is shown in Figure 5 and 6.

It has been noticed from the plot shown in Figures 5 and 6 that the lowest crop yield is observed as 19.31 ton/ ha in the year 2024 wherein November precipitation is $57.73 \mathrm{~mm}$ and August precipitation is $96.12 \mathrm{~mm}$ which is the highest precipitation during the years 2021-2050 under the RCP4.5 scenario. The highest crop yield is observed in the year 2039 as 30.0 ton/ha for which precipitation in the month of November is $17.09 \mathrm{~mm}$ which is near to lowest value and minimum temperature in the month of April 20.15 is highest among all years under RCP4.5. Similarly, the climate variables generated under RCP8.5 are comparing with the predicted grape yield

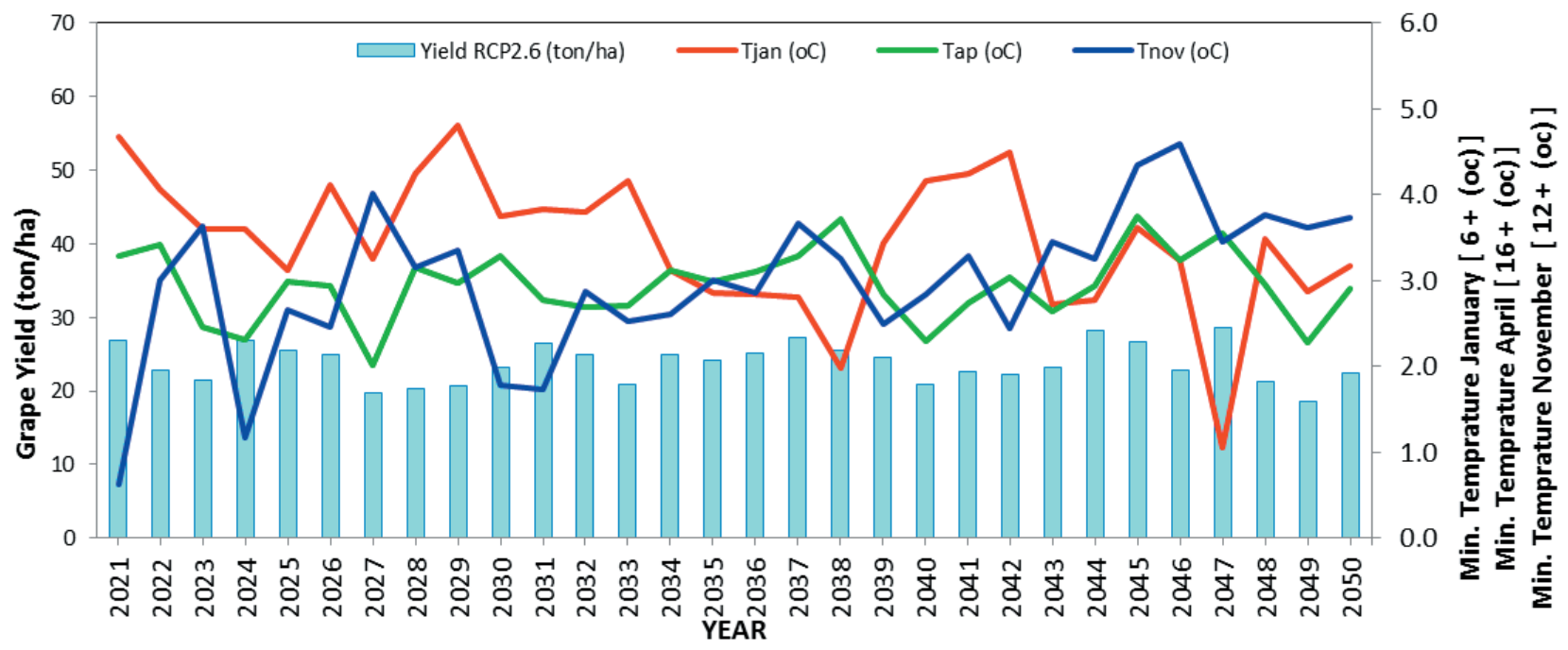

Figure 3. Climate plot between the model crop yield and minimum temperature in January, April, and November under RCP2.6 scenario (2021-2050). 


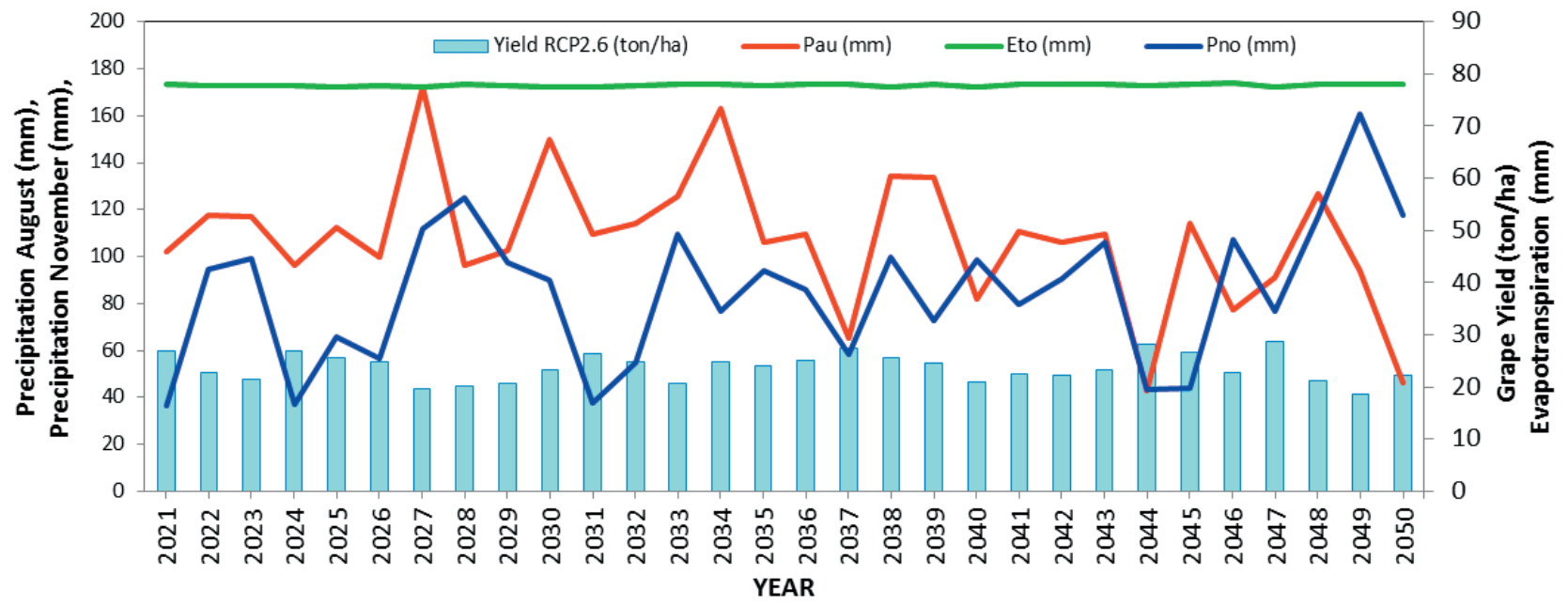

Figure 4. Climate plot between the model crop yield and evapotranspiration, precipitation in August and November under RCP2.6 scenario (2021-2050).

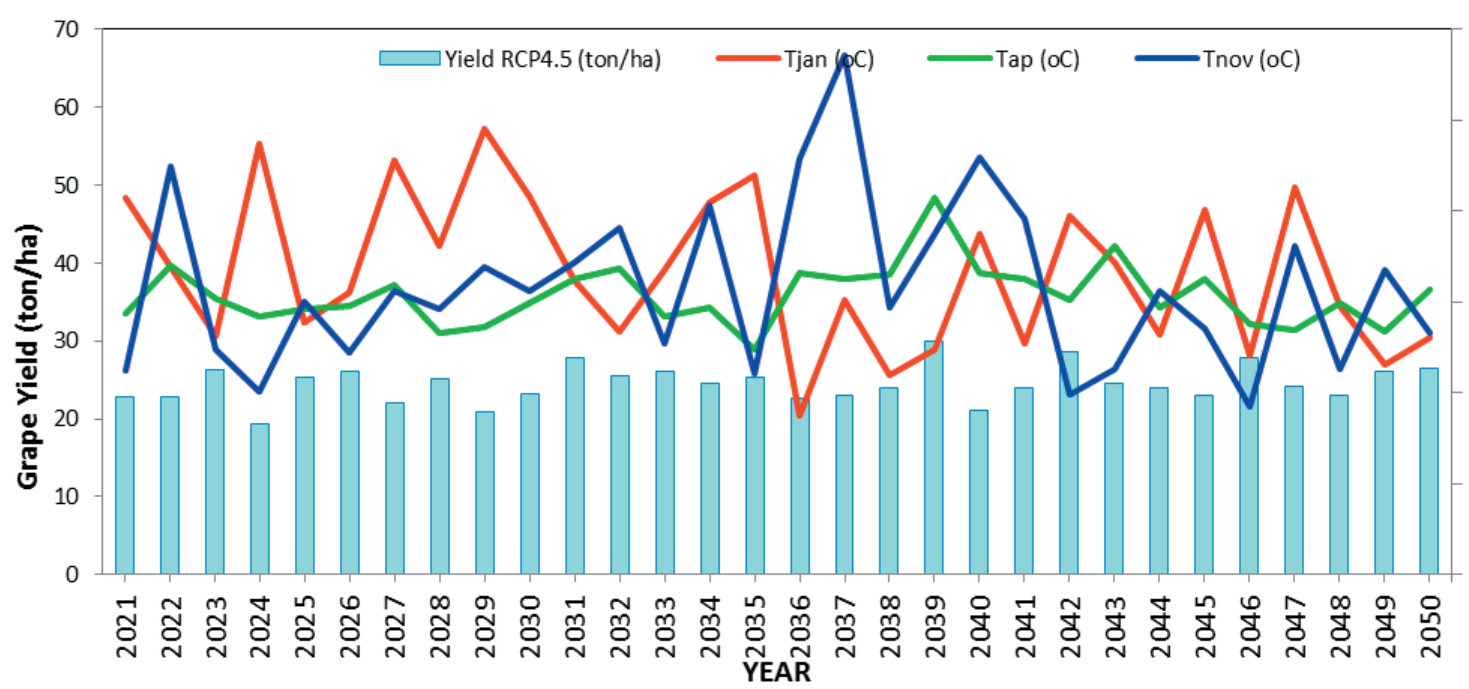

6.0

Figure 5. Climate plot between the model crop yield and minimum temperature in January, April, and November under RCP4.5 scenario (2021-2050).

during 2021-2050. Climate plot is shown below in Figure 7 and 8 .

It has been noticed from the plot shown in Figures 7 and 8 that the lowest crop yield is observed as 18.50 ton/ha in the year 2019 wherein January lowest value of minimum temperature as $10.71{ }^{\circ} \mathrm{C}$. The maximum crop yield is observed in the year 2039 as 30.40 ton/ha for which November precipitation is $6.44 \mathrm{~mm}$ which is lowest among all year under RCP 8.5.

\subsection{Model response variability}

A comparative study is carried out to find model yield responses in terms of current and future climate. The developed model (Eq. 13) is considered to estimate grape yields in context to the current climate and future climate under three future climate scenarios such as RCP2.6, RCP4.5, and RCP8.5. The current climate is considered during the period of 1991-2016 taken same as considered in the previous analysis. The future climate is derived using SDSM for the period of 2021-2050. Devel- 


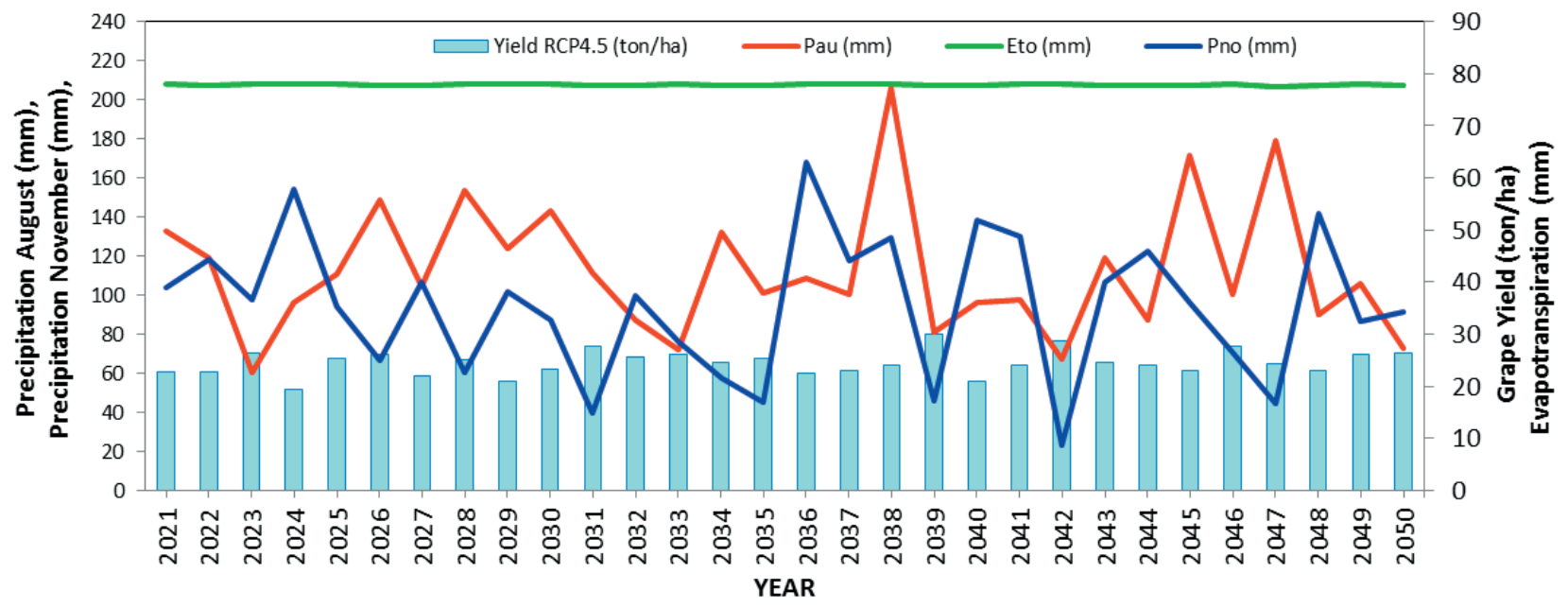

Figure 6. Climate plot between the model crop yield and evapotranspiration, precipitation in August and November under RCP4.5 scenario (2021-2050).
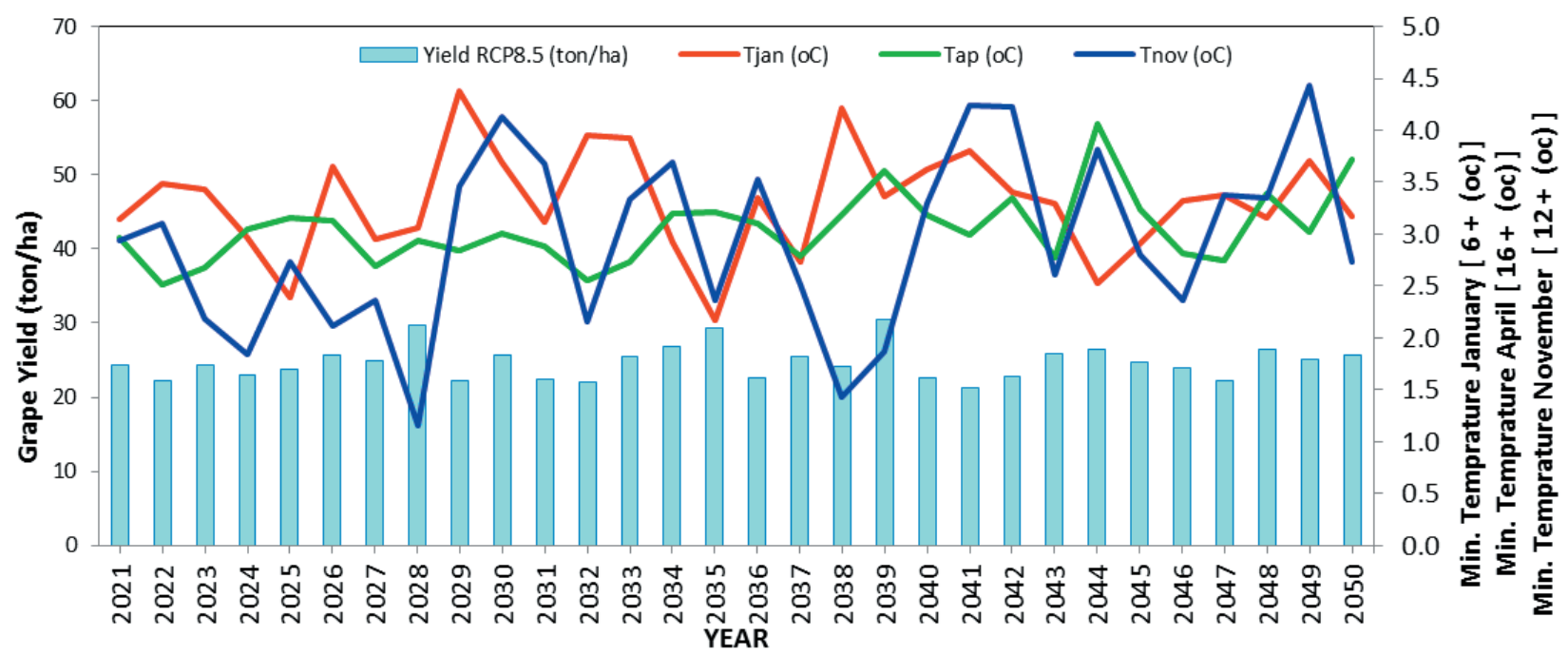

Figure 7. Climate plot between the model crop yield and minimum temperature in January, April, and November under RCP8.5 scenario (2021-2050).

oped ACGY model (Eq. 13) is used to estimate grape yields for the current and future climate. The future climate is considered under the generated climate scenarios as RCP2.6, 4.5 and 8.5 derived from SDSM under CIMIP5 experiments. The estimated crop yield is then compared in box and whisker plot to understand the model response variability with the current and future climate as shown in Figure 9.

It is observed from the Figure 9 that the median yield is observed as $23.2 \mathrm{t} / \mathrm{ha}$ for the current climate and lower and upper quartile values are observed to be away from median values as compare to all RCPs yield values. Upper and lower fence values are also away from median values as compare to all RCP yield values. Whereas, future climate median yields are observes as $24.1 \mathrm{t} / \mathrm{ha}$ under RCP 2.6, $24.52 \mathrm{t} / \mathrm{ha}$ and $24.72 \mathrm{ton} / \mathrm{ha}$ under RCP4.5 and RCP8.5 scenarios respectively. The lower and upper quartile values of RCP2.6, 4.5 and 8.5 are observed near to their median values as compared to yield values obtained for current climate. Under RCP2.6 minimum yield (lower fence) is 18.63 ton/ha and maximum yield (upper fence) is 28.64 ton/ha which 


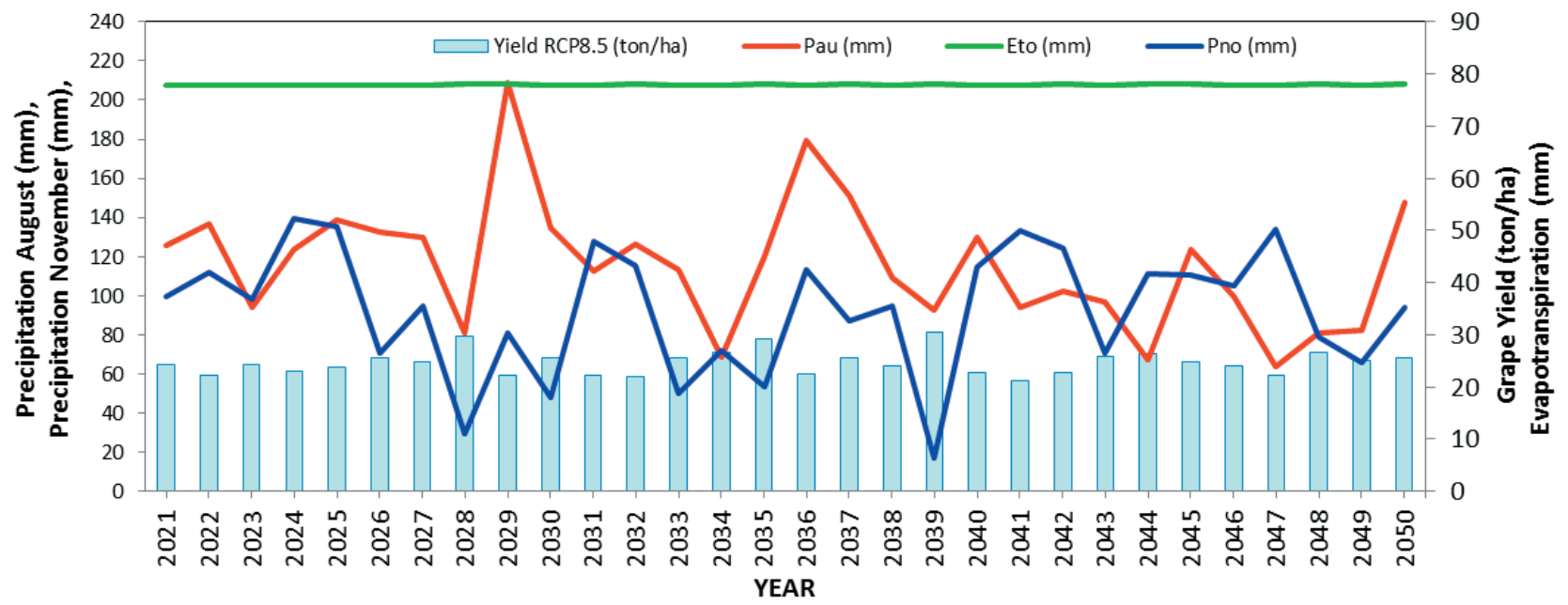

Figure 8. Climate plot between the model crop yield and evapotranspiration, precipitation in August and November under RCP8.5 scenario (2021-2050).

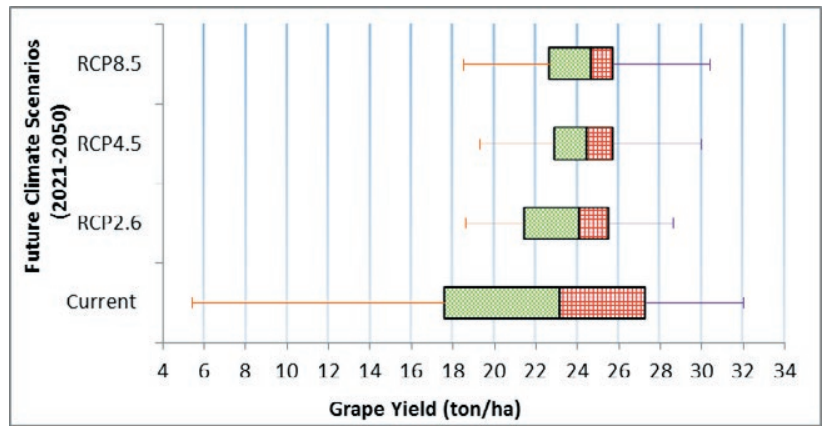

Figure 9. Box plot of model response variability with reference to current and future climate.

are near to median yield $24.12 \mathrm{t} / \mathrm{ha}$ as compare to the current climate values. RCP4.5 shows $19.31 \mathrm{t} /$ ha lower fence and 30.00 ton/ha upper fence which are nearer to median yield $24.52 \mathrm{t} / \mathrm{ha}$ as compare to current yield and also RCP8.5 shows $18.50 \mathrm{t} / \mathrm{ha}$ lower fence and $30.40 \mathrm{t} /$ ha upper fence yields are near to median yield $24.72 \mathrm{t} /$ ha as compare current yield values. It is observed from the model response variability that the grape yield of the future climate is showing the increase in yield as compared to the current climate.

\subsection{Future grape yield scenario}

In order to develop the grape yield scenarios, projected climate obtained from SDSM is used. Future yield scenarios are developed during the years 2021 to 2050 using ACGY model Eq. (13). All model parameters are obtained up to the year 2050 under RCP2.6, RCP4.5, and RCP8.5. The crop yield scenario is generated by considering the existing field management practices like irrigation as drip irrigation, soil type as clay base soil (black cotton soil), fertilizers as per soil nutrient value, pesticides, and tillage are considered as common practices adopted in the study area. Using developed ACGY model Eq.(13) and projected climate scenario under RCP2.6, 4.5 and 8.5 , grape yield scenario is generated. The obtained grape yield scenario under three RCPs during the year 2021 to 2050 is shown below in Figure 10.

It is observed from the Figure 10 that under RCP2.6 the lowest crop yield of 18.63 ton/ha is observed in the year 2049. This is due to the fact that precipitation occurred in the month of November of $72 \mathrm{~mm}$ which is the highest rainfall predicted in half a century. The maximum crop yield is found in the year 2047 as 28.64 $\mathrm{t} / \mathrm{ha}$ due to the fact that August precipitation is observed as $91.01 \mathrm{~mm}$ and November precipitation as $34.53 \mathrm{~mm}$ which are observed near to the lowest values of precipitation. Under RCP4.5, it is observed that the lowest crop yield of $19.31 \mathrm{t} / \mathrm{ha}$ in the year 2024 is predicted with November precipitation as $57.73 \mathrm{~mm}$ and August precipitation $96.12 \mathrm{~mm}$ which are nearer to its highest value. The highest crop yield is observed in the year 2039 as $30.00 \mathrm{t} / \mathrm{ha}$ for which November precipitation is $17.09 \mathrm{~mm}$ and August precipitation $80.75 \mathrm{~mm}$ which are observed near to lowest values. According to the RCP8.5 scenario, it is indicated that the lowest crop yield of $21.01 \mathrm{t} / \mathrm{ha}$ in the year 2041 is indicated with November precipitation of $125.25 \mathrm{~mm}$ and August precipitation $100.02 \mathrm{~mm}$ which are nearer to their highest values. The 


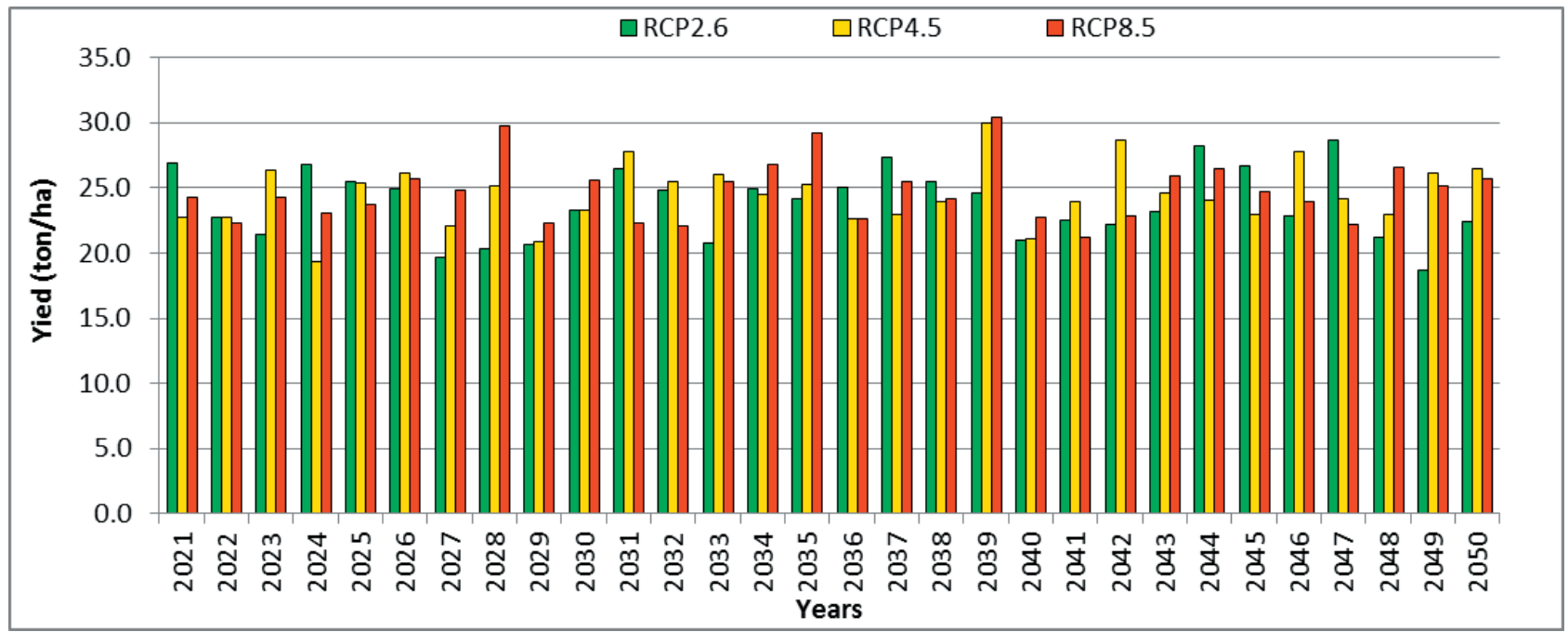

Figure 10. Grape yield scenario under RCP2.6, 4.5 and 8.5 using developed ACGY model (Eq. 13) (2021-2050).

highest crop yield is found in the year 2039 as $30.40 \mathrm{t} /$ ha for which November precipitation is $6.44 \mathrm{~mm}$ and August precipitation $92.97 \mathrm{~mm}$ which are observed nearer to their lowest values.

\subsection{Statistical performance of developed ACGY model (Eq.13)}

The predicted climate data is considered during the year 2011 to 2016. Using this predicted data under three RCPs and developed ACGY model Eq. (13) the yield is estimated during the year 2011-2016. The statistical fitness of the developed ACGY model (Eq.13) over the projected data for the duration of 2011-16 is checked using statistical tests as discrepancy ratio (r), standard deviation of the discrepancy ratio (r), mean percentage error (MPE) and standard deviation of MPE. The tests are already discussed in detail in section 5.11. Obtained results of all tests are shown in the Table 6.

It is observed that developed ACGY model (Eq.13) found performing most satisfactorily under RCP2.6. From the obtained results of statistical performance, it is observed that the developed ACGY model (Eq.13) is overall performing satisfactorily for the projected climate data obtained under different climate scenarios as RCP 2.6, 4.5 and 8.5. The following section discussed the projected grape yield using proposed irrigation methods using developed ACGY model and projected climate data.

\section{CONCLUSIONS}

The multi-regression analysis is carried out to obtain the final form of the ACGY model. The developed agroclimatic grape yield (ACGY) model (Eq.13) is statistically tested for its fitness. The discrepancy ratio, the standard deviation of discrepancy ratio, mean percentage error and standard deviation of mean percentage error for the developed model is obtained as $1.03,0.19,0.03 \%$ and 0.19 respectively. Sensitivity analysis is carried out for the developed ACGY model using the parametric sensitivity method. Based on the obtained results of the statistical tests the developed ACGY model (Eq.13) is recommended for its use to estimate the grape yield. To understand

Table 6. Results of the statistical performance of the developed ACGY model Eq.(13) (2011-2016).

\begin{tabular}{lcccccc}
\hline & \multicolumn{2}{c}{ RCP2.6 } & \multicolumn{2}{c}{ RCP4.5 } & \multicolumn{2}{c}{ RCP8.5 } \\
\cline { 2 - 7 } Statistical Test & $\begin{array}{c}\text { Discrepancy } \\
\text { Ratio (r) }\end{array}$ & $\begin{array}{c}\text { Mean \% Error } \\
\text { (MPE) }\end{array}$ & $\begin{array}{c}\text { Discrepancy } \\
\text { Ratio (r) }\end{array}$ & $\begin{array}{c}\text { Mean \% Error } \\
(\text { MPE) }\end{array}$ & $\begin{array}{c}\text { Discrepancy } \\
\text { Ratio (r) }\end{array}$ & $\begin{array}{c}\text { Mean \% Error } \\
(\text { MPE) }\end{array}$ \\
\hline mean & 1.08 & $8 \%$ & 1.16 & $16 \%$ & 1.22 & $22 \%$ \\
SD & 0.58 & 0.58 & 0.65 & 0.65 & 0.80 & 0.80 \\
\hline
\end{tabular}


the most sensitive parameters of the ACGY model Eq. (13), sensitivity analysis is carried out using the methods of parametric and component sensitivity method. From the obtained results of sensitivity analysis, it is found that sum of monthly mean evapotranspiration, the monthly mean minimum temperature in April and precipitation in August parameters found to be more sensitive. It is recommended that the developed ACGY model Eq. (13) can be used for the estimation of grape yield of the study area. It is observed from the sensitivity analysis that the grape is found highly sensitive to climatic parameters. Therefore, in order to know the grape yield in advance, it is necessary to know the future climate. By knowing future climate it is possible to generate the grape yield scenarios using developed agro-climatic grape (ACGY) model (Eq. 13).

Grape yield projections are generated using future predicted climate data. According to the analysis carried out grape crop showing increasing yield in the future i.e. up to 2050 as compared to current yield. The analysis of grape yield shows that annual evapotranspiration and minimum temperature in the month of April shows in accordance impact on the yield, whereas, the minimum temperature in January and November, precipitation in August and November shows an adverse impact on the yield. From the obtained results of statistical performance of the developed model, it is observed that model is performing better for future yield predictions under three RCP scenarios.

\section{REFERENCES}

Abbaspour K.C., (1994). "Bayesian risk methodology for crop insurance decisions." Agri. Forest Meteorol., 71:297-314.

Abraha M.G., Savage M.J.,(2006)."Potential impacts of climate change on the grain yield of maize for the midlands of KwaZulu-Natal, South Africa."Agric. Ecosyst. Environ.,115, 150-60.

Adams R.M., Wu J., and Houston L., (2003). "Climate Change and California, Appendix IX: The effects of climate change on yields and water use of major California crops." California Energy Commission, Public Interest Energy Research (PIER), Sacramento, 21-32.

Adsule P.G., (2013). "Good agriculture practices for production of quality table grapes." report of a national research center for grapes, Manjari, Pune, 1-83.

Akpalu W., Hassan R.M., Ringler C., (2008). "Climate variability and maize yield in South Africa: results from GME and MELE methods." Environment and production technology division IFPRI discussion paper; 1-12.
APDEA (2016) Agriculture production development and Economics authority India, Export of Agro. Food Products Report, 20-32.

Arora V.K., and Boer G.J..(2014). "Terrestrial ecosystems response to future changes in climate and atmospheric $\mathrm{CO}_{2}$ concentration." Bio geosciences, 11(15), 41574171.

Bowden, W. B., Bormann F. H., (1986). "Transport and loss of nitrous oxide in soil water after forest clearcutting." Science 233, 867- 869.

Droogers P., (2004). "Adaptation to climate change to enhance food security and preserve environmental quality: an example for southern Sri Lanka." Agr. Water Manag., 66:15-33.

FAO (2016). "FAO-OIV FOCUS 2016 Table and dried grape" $32-33$

Gupta S.G., (1981). "Fundamental of statistics, Himalaya publishing house." 7, 27.1-27.31.

Hamby D.M. (1994). "A review of techniques for parameter sensitivity analysis of environmental models." Environmental monitoring and assessment 32: 135154.

Hoogenboom G. (2000). "Contribution of agrometeorology to the simulation of crop production and its applications." Agric. Forest Meteorol, 103:137-57.

Hoskins Brian J. (1980). "Representation of earth topography using spherical harmonics" notes and correspondence of American metrological society, 111115.

IPCC, (2013). "Climate Change 2013, the physical science basis, contribution of working group 1 to 5 assessment report of the Intergovernmental Panel on Climate Change." Cambridge, United Kingdom and New York, USA, Cambridge University Press, Cambridge.

Netzer, Y., Yao, C.R., Shenker, M., Bravdo, B.A., Schwartz A., (2009). "Water use and the development of seasonal crop coefficients for Superior Seedless grapevines trained to an open-gable trellis system." Irrigation Science, 27, 109-120.

Nikolić, D., Muresan R.C., Feng, W., Singer W., (2012). "Scaled correlation analysis: a better way to compute a cross-correlogram." European Journal of Neuroscience, 1-21.

Popova Z., Kercheva M., (2005). "CERES model application for increasing preparedness to climate variability in agricultural planning-risk analyses." Phys. Chem. Earth., 30:17-24.

Saxena Mamta, (2014). "Handbook on horticulture statistics 2014." Government of India Ministry of Agriculture Department of Agriculture and Cooperation New Delhi, 25-26. 
Srinivastav A.K. (2015). "Agriculture statistics system in India." NSSO (FOD), 1-2.

Taylor K.E., Stouffer R.J., and Meehl G.A., (2012). "An overview of CMIP5 and the experiment design." Bulletin of the American Meteorological Society, 93(4), 485-498.

Van Vuuren D.P., Edmonds, J.A., Kainumaa M., Riahi K., and Weyant, J., (2011). "A special issue on the RCPs." Climate Change, 109 (1), 1-4.

Wilby R.L., Dawson C.W., Barrow E.M. (2002). "SDSM - a decision support tool for the assessment of regional climate change impacts." Environmental Modelling \& Software 17, 147-159.

Yinhong K., Shahbaz K., Xiaoyi M., (2009). "Climate change impacts on crop yield, crop water productivity, and food security - A review" Progress in Natural Science 19, 1665-1674.

Zhang R., and Shen X., (2008). "On the development of the GRAPES-A new generation of the national operational NWP system in China." Chinese Science Bulletin, 53(22):3429-3432. 